\title{
Recrystallization of a Ti-45Ni-5Cu Cold-worked Shape Memory Alloy Characterized by Thermoelectric Power and Electrical Properties
}

\author{
Daniel Enrique Soto-Parra ${ }^{a}$,Horacio Flores-Zúñiga ${ }^{a}$,Enrique López Cuéllar ${ }^{b, c *}$, Raul Armando \\ Ochoa-Gamboa ${ }^{d}$, David Ríos-Jara ${ }^{a}$ \\ ${ }^{a}$ Instituto Potosino de Investigación Científica y Tecnológica - IPICYT, \\ División de Materiales Avanzados, Camino a la Presa San José 2055 Col. \\ Lomas 4a. sección C.P. 78216, San Luis Potosí, S.L.P., México \\ ${ }^{\text {} P o s g r a d o ~ d e ~ F I M E, ~ U n i v e r s i d a d ~ A u t o ́ n o m a ~ d e ~ N u e v o ~ L e o ́ n, ~ A . P . ~} 076$ Suc. " $F$ ", Cd. Universitaria, \\ C.P. 66450, San Nicolás de los Garza, N.L., México \\ ${ }^{c}$ CIIDIT, Universidad Autónoma de Nuevo León, parque PIIT km. 10 autopista al Aeropuerto \\ Internacional de Monterrey, Apodaca, N.L., México \\ ${ }^{d}$ Centro de Investigación en Materiales Avanzados S.C. Miguel de Cervantes 120, \\ Complejo industrial Chihuahua. 31109 Chihuahua México
}

Received: January 31, 2014; Revised: May 21, 2014

\begin{abstract}
The recrystallization of a cold-worked shape memory alloy (SMA) without R-phase transition, i.e. the Ti-45.0Ni-5.0 Cu (\% at.), has been studied by thermoelectric power (TEP) technique and electrical resistivity change $(\mathrm{D} \rho)$ on several heat treated samples after cold working. This study was also supported by differential scanning calorimetry (DSC), transmission electron microscopy (TEM) and hardness Vickers (HV) measurements. Transformation temperatures show an increase with heat treatment temperature, while hysteresis decreases. Hardness values decrease with aging temperature for the same heat treatment time. No important changes were observed in electrical resistivity with heat treatment temperature, except at $300^{\circ} \mathrm{C}$. TEP results show an important increase with heat treatment temperature, and a linear relationship was found between hardness and thermoelectric power. With this correlation between TEP and microhardness it is possible to predict its mechanical response by knowing its TEP, so this correlation could be important for applications.
\end{abstract}

Keywords: effect of cold work, recrystallization, shape memory alloy, thermoelectric power

\section{Introduction}

Ti-Ni alloys exhibit particular physical properties such as pre-transformation behaviors and very low elastic anisotropy ${ }^{1}$ and they can be used in robotic and actuator applications ${ }^{2-4}$. Their martensitic transformation temperatures $\left(\mathrm{M}_{\mathrm{s}}\right)$ are close to room temperature. Moreover, the addition of $\mathrm{Cu}$ is very important for applications in robotic devices or actuators ${ }^{5,6}$ because it inhibits the formation of R-phase which is an undesirable phase that causes a nonlinear correlation between the strain $(\varepsilon)$ and the change in electrical resistivity $\left(\Delta \mathrm{r} / \mathrm{r}_{0}\right)$. When $5 \%$ at. of $\mathrm{Cu}$ is added, a linear correlation is achieved, which allows very good control of the position of the actuator ${ }^{2-8}$.

The correlation study of the microstructural evolution during the recovery process after an "amorphization" with mechanical, electrical and thermal properties is important for the applications of $\mathrm{Ti}-\mathrm{Ni}-\mathrm{Cu}$ system, because by controlling the microstructure with the thermomechanical treatment, the mechanical or electrical response of the alloy can be predicted, for example the position of an actuator. The process of "amorphization" can be explained as the conversion of a crystalline material into an amorphous

*e-mail: lopezcuellar@gama.fime.uanl.mx one. On the other hand, thermomechanical treatments in the Ti-Ni alloy have been studied in different works ${ }^{3,9-13}$ in order to choose a more robust process for the required operating conditions and in some cases, these studies have attained a state of "amorphization"11-14 but very few works of amorphization adding $\mathrm{Cu}$ into the Ti-Ni alloy have been done. It must be noted that, thermomechanical treatments of the Ti-Ni45-Cu5 alloy have been previously reported by López Cuéllar et al., ${ }^{7,16}$, mostly focused upon the change in electrical and mechanical properties during the thermomechanical life cycle, but without relate microstructural changes with the process of amorphizationrecrystallization. Koike et al. have reported that a $60 \%$ reduction of sample obtained by cold-rolling at room temperature produces a crystal-amorphous transformation in $\mathrm{Ti}-50.8 \mathrm{Ni}^{[14]}$. The resulting microstructure is partly amorphous with amorphization due to the dislocation density in highly deformed regions varying between $10^{13}$ and $10^{14} \mathrm{~cm}^{-2}$, with an energy equivalent to the crystallization energy ${ }^{14}$. Furthermore, since the amorphous state appears in shear bands, these works suggest that the amorphous state is caused by the shear instability associated with a high dislocation grain size in Ti-Ni alloy after $40 \%$ of reduction 
by cold work ${ }^{15}$. In this sense, this amorphization produced by heavy deformation of the Ti-Ni alloy, is interesting because the grain size of amorphous specimens after recrystallization can be much smaller than that obtained by ordinary methods. This, in turn, may improve mechanical properties.

M. Perez ${ }^{17}$ reported that the TEP of an alloy can be affected at different levels due to all the lattice defects (solute atoms, dislocations, precipitates, etc) which may disturb the electronic or elastic properties of the material and subsequently, induce a TEP variation. M. Perez ${ }^{17}$ also mentioned that as far as precipitates are concerned as a second phase, they can be neglected, except if they are coherent or if their volume fraction is high, which is not our case. Then, in our study according with M. Perez, only the effect of dislocations on TEP should be considered. But it must be noted that during the process of cold-worked of the Ti-Ni-Cu system, not only dislocations are induced, also the orientation of variants is introduced ${ }^{18}$, and this anisotropic orientation clearly affects the TEP of the alloy as previously reported by López Cuéllar et al. ${ }^{16}$. And with a heat treatment process after cold working, the diminution of dislocations and the decrease of defects due to the grain boundary growth will take place. Then, taking into account the discussion above, the evolution of the TEP for the Ti-Ni-Cu alloy during this thermomechanical process should be affected by the dislocations induced during cold working, the orientation of variants from cold working and the change of grain size caused by the thermomechanical process.

In our work, an extensive recrystallization study of the Ti-Ni45-Cu5 alloy at different heat treatment temperatures is presented after an amorphization process. For this, TEM, DSC, microhardness, electrical resistivity and thermoelectric power techniques were used to examine this material after the amorphization. Results indicate that heat treatments from 330 to $428^{\circ} \mathrm{C}$ for one hour, produce only recovery and recrystallization, while higher temperatures promote an increase of grain size after the formation of an amorphous state. Moreover, results have shown that from DSC, it was not possible to detect the beginning of this recovery and/or recrystallization. However, from electrical measurements and TEP, this phenomenon was detectable. In addition, TEP technique was sensitive to the anisotropic orientation of variants induced during the cold work. Finally, a correlation between TEP and microhardness was observed, so, it is possible to predict its mechanical response and its microstructure with this information, which is not possible with electrical resistivity analysis.

\section{Experimentation}

A wire of Ti-45.0Ni-5.0Cu (\% at.) with $0.81 \mathrm{~mm}$ in diameter, was manufactured by Advanced Materials and Technologies n.v. (AMT Inc.) at SWISSMETAL. The start and finish of the martensitic transition temperatures $\left(M_{s}, M_{f}\right)$ and the reverse martensitic transition temperatures $\left(\mathrm{A}_{\mathrm{s}}, \mathrm{A}_{\mathrm{f}}\right)$ of the as-received material were $\mathrm{M}_{\mathrm{s}}=35.1^{\circ} \mathrm{C}, \mathrm{M}_{\mathrm{f}}=21.3^{\circ} \mathrm{C}$, $\mathrm{A}_{\mathrm{s}}=44.9^{\circ} \mathrm{C}$ and $\mathrm{A}_{\mathrm{f}}=60.5^{\circ} \mathrm{C}$, with a thermal hysteresis around of $26.2^{\circ} \mathrm{C}$. The wire of $0.81 \mathrm{~mm}$ of diameter was cold-worked in a laboratory cold rolling machine manually operated, to obtain sheets of $2 \mathrm{~mm}$ in width and $0.25 \mathrm{~mm}$ in thickness in one step.
The cold-worked sheets were heat treated at different temperatures and times as indicated in Table 1. Heat treatments (HT) were carried out to recrystallize the deformed material and were chosen assuming that for metallic alloys, the temperature of recrystallization is between 0.3 and $0.6 \mathrm{~T}_{\mathrm{M}}$, where $\mathrm{T}_{\mathrm{M}}$ is the melting temperature of the particular alloy.

The recrystallization process in the cold-worked Ti-Ni45-Cu5alloy, has been studied by DSC with a TA Instruments DSC2920, in a range between $-80^{\circ} \mathrm{C}$ to $100^{\circ} \mathrm{C}$ with ramps $10^{\circ} \mathrm{C} / \mathrm{min}$ in little samples close to $5 \mathrm{mg}$. Transition temperatures were determined at fractions 0.05 and 0.95 of the total transformed phase during the martensitic transition $\left(\mathrm{M}_{\mathrm{S}}, \mathrm{M}_{\mathrm{f}}\right)$ and the reverse martensitic transition $\left(\mathrm{A}_{\mathrm{S}}, \mathrm{A}_{\mathrm{f}}\right)$. Samples were studied with a TEM (PHILIPS CM 200). The electrical resistivity measurements were obtained during the martensitic and the reverse martensitic transition by four points method in $8 \mathrm{~cm}$ cold-worked sheets. During electrical resistivity measurements, the cooling rate was $1.2^{\circ} \mathrm{C} / \mathrm{min}$ and the heating rate was $4^{\circ} \mathrm{C} / \mathrm{min}$. Thermoelectric power measurements were performed at room temperature in a contact Techlab equipment with Fe blocks with an accuracy achieved in the laboratory of $\pm 0.002 \mathrm{mV} / \mathrm{K}^{[16,17]}$. Two reference metal blocks electrically and thermally isolated are maintained at temperatures 10 and $20^{\circ} \mathrm{C}$ each block $(\Delta \mathrm{T}=10 \mathrm{~K})$. The sample is pressed on these two blocks with a good electrical and thermal contact. A thermocouple is therefore formed giving rise to a voltage $\Delta \mathrm{V}$ between the two blocks. The relative TEP of the sample in relation to the reference metal at a temperature $\mathrm{T}$ is given by: $\Delta \mathrm{S}=\Delta \mathrm{V} / \Delta \mathrm{T}$. Experimental values of TEP were obtained at $\mathrm{T}=293 \mathrm{~K}$. Microhardness was measured 10 times and their average was calculated at room temperature under $1000 \mathrm{~g}$ of force during 10 seconds in a microhardness tester FUTURE TECH.

\section{Results and Discussion}

\subsection{Microstructure}

Figures $1 \mathrm{a}$ to $1 \mathrm{~g}$ show TEM images and diffraction patterns of the cold worked samples without heat treatment (HT) and after HT1 to HT6 respectively (see Table 1). These samples belong to the same cold worked wire. Diffraction patterns in Figure 1 show the evolution of the rings as well as the recovery process corresponding at the same crystalline phase. The rings in Figure 1 for HT1 and HT2 show an austenitic B2 crystalline phase, but for HT3, HT4, HT5, and HT6, the rings show the typical martensitic B19' crystalline phase. As expected, when the temperature is increased, more

Table 1. Heat treatments carried out after cold working.

\begin{tabular}{ccc}
\hline Heat Treatment & Temperature $\left({ }^{\circ} \mathbf{C}\right)$ & Time $(\mathbf{h})$ \\
\hline HT1 & 330 & 1 \\
HT2 & 390 & 1 \\
HT3 & 428 & 1 \\
HT4 & 485 & 1 \\
HT5 & 485 & 2 \\
HT6 & 650 & 0.5 \\
\hline
\end{tabular}



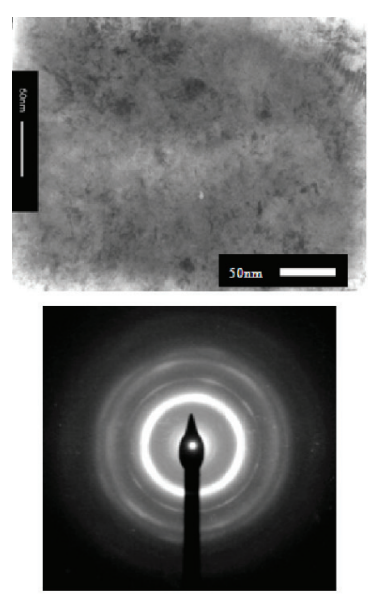

(a) Cold worked
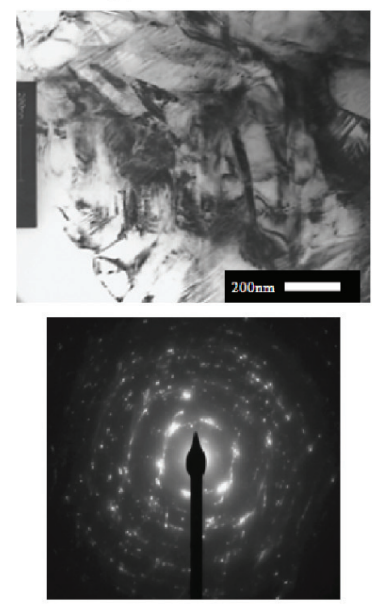

(e) $485^{\circ} \mathrm{C}(1 \mathrm{~h})$
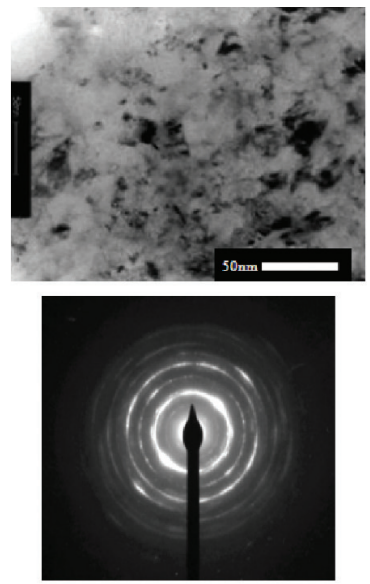

(b) $330{ }^{\circ} \mathrm{C}(1 \mathrm{~h})$
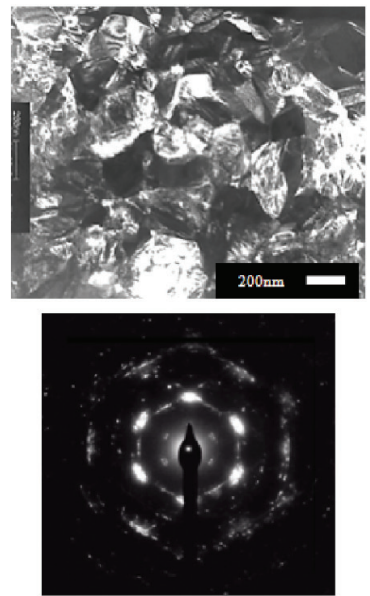

(f) $485^{\circ} \mathrm{C}(2 \mathrm{~h})$
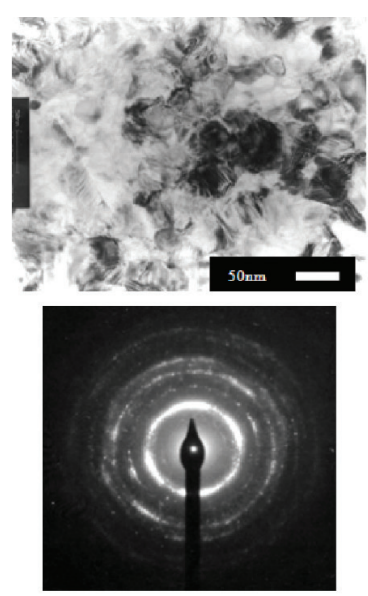

(c) $390^{\circ} \mathrm{C}(1 \mathrm{~h})$
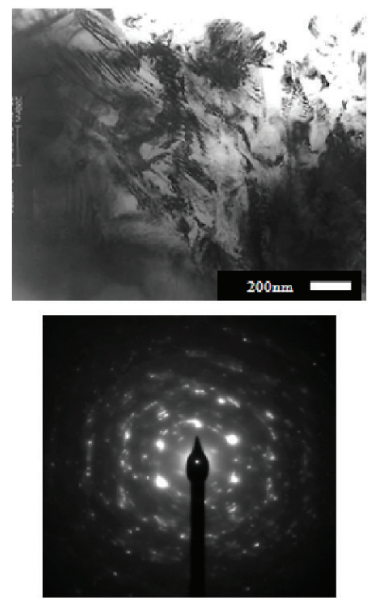

(g) $650{ }^{\circ} \mathrm{C}(0.5 \mathrm{~h})$
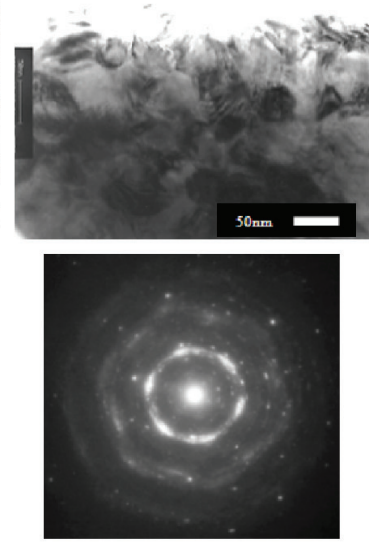

(d) $428^{\circ} \mathrm{C}(1 \mathrm{~h})$

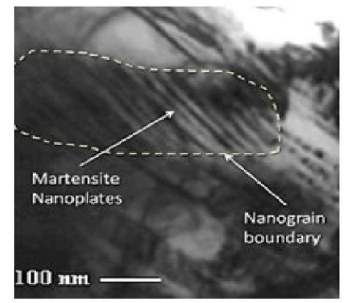

Magnification from

Figure 1-g

(h) $650{ }^{\circ} \mathrm{C}(0.5 \mathrm{~h})$

Figure 1. TEM images of Ti-Ni-Cu: a) After cold work without HT, b) After HT1 $\left(330^{\circ} \mathrm{C} 1 \mathrm{~h}\right)$, c) After $\mathrm{HT} 2\left(390^{\circ} \mathrm{C} 1 \mathrm{~h}\right)$, d) after $\mathrm{HT} 3$ $\left.\left(428^{\circ} \mathrm{C} 1 \mathrm{~h}\right), \mathrm{e}\right)$ After HT4 $\left.\left(485^{\circ} \mathrm{C} 1 \mathrm{~h}\right), \mathrm{f}\right)$ after $\left.\mathrm{HT} 5\left(485^{\circ} \mathrm{C} 2 \mathrm{~h}\right), \mathrm{g}\right)$ after $\mathrm{HT} 6\left(650^{\circ} \mathrm{C} 0.5 \mathrm{~h}\right)$ and $\left.\mathrm{h}\right)$ Magnification from Figure $\left.1 \mathrm{~g}\right)$.

Table 2. Transformation temperatures at $10 \%$ and $90 \%$ of transformation, hysteresis and mean grain size for different heat treatments.

\begin{tabular}{|c|c|c|c|c|c|c|}
\hline Heat Treatment & $\mathbf{M}_{\mathrm{S}}\left({ }^{\circ} \mathbf{C}\right)$ & $\mathbf{M}_{\mathrm{f}}\left({ }^{\circ} \mathbf{C}\right)$ & $\mathbf{A}_{\mathrm{S}}\left({ }^{\circ} \mathbf{C}\right)$ & $\mathbf{A}_{\mathrm{f}}\left({ }^{\circ} \mathbf{C}\right)$ & $\mathbf{H}_{\mathrm{t}}\left({ }^{\circ} \mathbf{C}\right)$ & Mean grain size $(\mathbf{n m})$ \\
\hline As received & 35.1 & 21.3 & 44.9 & 60.5 & 26.2 & - \\
\hline $\begin{array}{l}\text { HT1 } \\
\left(1 \mathrm{~h} \text { at } 330^{\circ} \mathrm{C}\right)\end{array}$ & - & - & - & - & - & 30 \\
\hline $\begin{array}{l}\mathrm{HT} 2 \\
\left(1 \mathrm{~h} \text { at } 390^{\circ} \mathrm{C}\right)\end{array}$ & 5.9 & -15.8 & 18.7 & 45.5 & 38.3 & 32 \\
\hline $\begin{array}{l}\text { HT3 } \\
\left(1 \mathrm{~h} \text { at } 428^{\circ} \mathrm{C}\right)\end{array}$ & 33.5 & 20.9 & 43.0 & 57.1 & 23.6 & 40 \\
\hline $\begin{array}{l}\text { HT4 } \\
\left(1 \mathrm{~h} \text { at } 485^{\circ} \mathrm{C}\right)\end{array}$ & 48.8 & 42.6 & 64.3 & 71.5 & 22.6 & 154 \\
\hline $\begin{array}{l}\text { HT5 } \\
\left(2 \mathrm{~h} \text { at } 485^{\circ} \mathrm{C}\right)\end{array}$ & 49.3 & 42.7 & 64.8 & 72.0 & 23.0 & 164 \\
\hline $\begin{array}{l}\mathrm{HT} 6 \\
\left(0.5 \mathrm{~h} \text { at } 650^{\circ} \mathrm{C}\right)\end{array}$ & 62.9 & 55.5 & 78.5 & 87.6 & 24.9 & 214 \\
\hline
\end{tabular}

recrystallization is observed, as indicated by better defined spots in the diffraction pattern and an increase in the size of the nanocrystals as is reported in Table 2 . An amorphous state is achieved after cold work, as can be observed in Figure 1a where a characteristically thick ring diffraction pattern is developed. After HT1, nanograins of around $30 \mathrm{~nm}$ size appear, and small changes on the ring pattern are induced, as can be observed in Figure 1b. This can be associated with the beginning of dislocation movements that develop the nanograin boundaries. However, the amorphous 
state and deformation are still important as it is shown in selected area diffraction pattern. Crystalline - amorphous ratio was not quantified in this study.

Between HT1 and HT2, no significant increase in mean grain size is observed (Figure 1b, c). For HT3 (Figure 1d), an increase in nanocrystal size to $40 \mathrm{~nm}$ was attained and electron diffraction pattern shows a recrystallized microstructure. Nanograins can be identified because some boundaries start to be developed around some dark and bright grains. For samples after HT4 and HT5 (Figures 1e and 1f, respectively), no precipitation was observed and martensitic nanoplates were better defined inside nanograins. For HT4 and HT5 (1 and 2 hours at $485^{\circ} \mathrm{C}$, respectively), the mean nanograin size is similar for both temperatures, at $154 \mathrm{~nm}$ and $164 \mathrm{~nm}$, respectively. In both cases, spots in the diffraction patterns start to appear sharper than for previous HT's. Finally, a mean grain size of $214 \mathrm{~nm}$ was observed after HT6 at $650^{\circ} \mathrm{C}$ for $30 \mathrm{~min}$ as shown in Figure 1g. Here again, martensitic nanoplates are clearly observed inside nanograins (see the magnification of Figure 1g). These results agree with previous reports on the formation of nanograins in $\mathrm{Ti}-\mathrm{Ni}$ and $\mathrm{Ti}-\mathrm{Ni}-\mathrm{Cu}$ alloys after thermomechanical treatments ${ }^{15,18,19}$.

\subsection{Differential Scanning Calorimetry (DSC)}

In Figure 2 the DSC curves obtained from the sample as received and for each of the heat treatments studied in this work are presented. Table 2 shows the martensitic transformation temperatures after each HT, as measured by DSC. For HT1 it was not possible to detect transformation temperatures by this technique due to the extent of amorphous state in the alloy. As the alloy starts to recrystallize above $390^{\circ} \mathrm{C}$, grain boundaries start to develop and martensitic transformation is recovered. For HT2, where martensitic transformation is first detected, the transformation hysteresis is about $15^{\circ} \mathrm{C}$ higher than that measured at higher HT temperatures, an indication of a reduction of the thermoelastic behavior. An increase in transformation temperatures is obtained with increasing HT temperatures. Grain size plays an important role on transformation temperatures. As previously reported $\mathrm{d}^{20,21}$, an increase in transformation temperatures with grain size growth takes place because the growth of martensite variants are limited by the grain boundaries. No significant change in transformation temperatures was observed with increasing time of $\mathrm{HT}$ at $485^{\circ} \mathrm{C}$ (HT4 and HT5). The transformation temperatures of the samples after $\mathrm{HT}$ at 485 and $650^{\circ} \mathrm{C}$ are higher than those of the as-received material, probably because the initial manufacturer's heat treatment caused a lower level of recrystallization than HT4, HT5, and HT6. Notwithstanding cold-worked sheets could present precipitates during recovery process due to the thermal treatment, which could affect transformation temperatures. The increase in transformation temperature appears to be correlated with the increase of the alloy's grain size, as it can be seen in Table 2 .

\subsection{Microhardness}

The mean hardness vs. HT temperature values are show in Figure 3. Values of hardness are in the range of those previously reported $^{16}$. The value of the lower line at $278 \mathrm{HV}$ corresponds to the as received alloy, and the reference upper line at $462 \mathrm{HV}$ corresponds to the cold-worked alloy without heat treatment. Normally the latter should be the highest value, but the alloy heat treated at $330^{\circ} \mathrm{C}$ (that is, HT1), shows an increment in hardness. This could be due to the microstructure after HT1, as shown in Figure 1b, where important amorphous zones are still present in the alloy with small nanograins. This unusual mixture of microstructures could lead to the measured increase in microhardness due to an anisotropic effect induced during the cold-working and the direction in which the microhardness test was carried out. Recovery seems to be reached at HT2, after that, an increase in the heat treatment (HT3 to HT6) promotes also a grain size growth, where a linear microhardness decrease is observed with the temperature. We assume that increasing on the grains size by heat treatment temperature produces an increase of residuary dislocation movements inside nanograin, which promote a stress relaxation and a microhardness decrease. For HT6 a more stable value is obtained, indicating that a minimum value of microhardness can be attained.

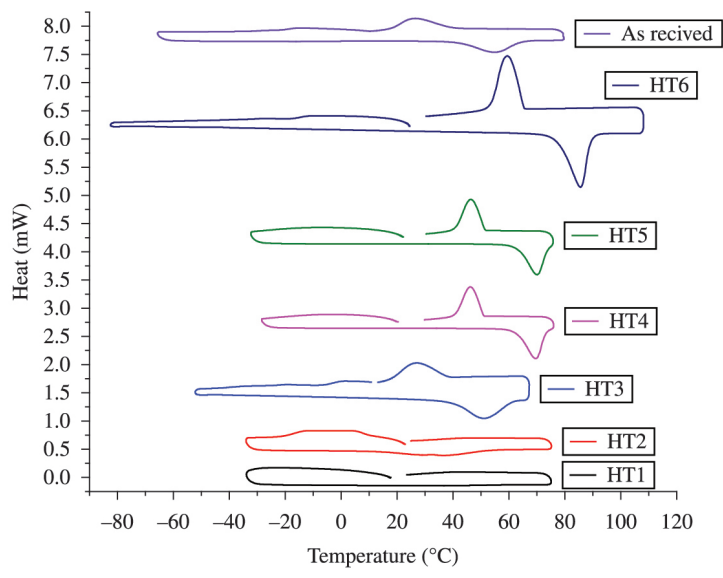

Figure 2. DSC peaks obtained from the states of the Ti-Ni-Cu samples.

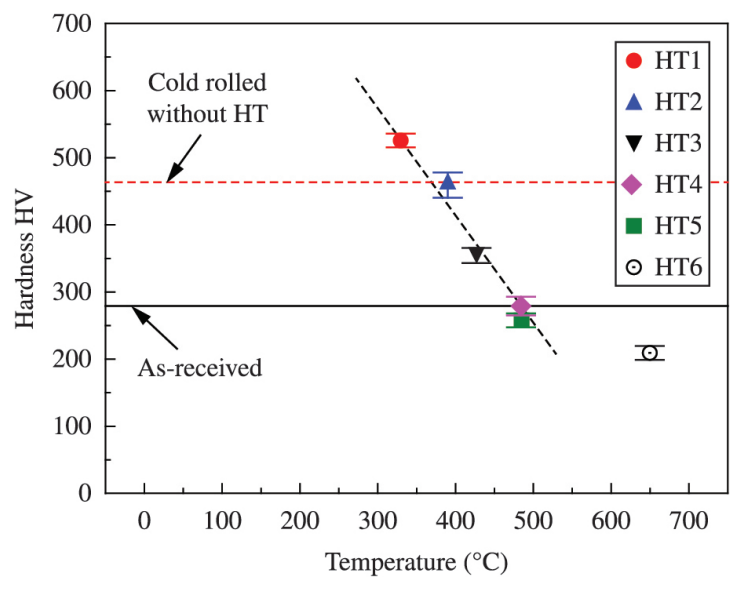

Figure 3. Microhardness vs. Temperature for each heat treatment. 


\subsection{Electrical resistivity}

Figures 4a-d show electrical resistivity vs. temperature curves for the as-received cold-worked and heat-treated (HT1-HT6) samples. Results of resistivity are in agreement with those reported in literature ${ }^{22}$. The as-received sample has a typical martensitic transformation behavior (Figure 4a) where the resistance of the low temperature phase (martensitic phase) has the highest value. As the high temperature phase (austenitic phase) starts, the resistance decreases with increasing temperature until the transformation to the martensitic phase is complete. If the sample is cooled, a reversible transformation occurs with hysteresis.

For the cold-worked alloy without HT, the transformation is blocked, as can be seen in the upper curve of Figure $4 \mathrm{~b}$, where only a small linear increase in resistivity with temperature is obtained. This is typical of materials without shape memory effect and agrees with results obtained by the DSC and microstructure analysis. When HT1 is carried out on the cold-worked sample, a different behavior is observed as shown in Figure 4b, where a small decrease in electrical resistivity occurs as the temperature increases. This observation suggests that the transformation in nanograins $(<30 \mathrm{~nm})$, observed in TEM images (see Figure $1 \mathrm{~b}$ ), may be taking place, even if it is not detectable by DSC, demonstrating that in this case that the sensitivity of the electrical resistivity technique is higher than DSC.

As the HT temperature HT increases, two changes are observed in the curves: (i) a typical increase in transformation temperatures and (ii) an increase in the extent of change in electrical resistivity, as show in Figures $3 \mathrm{c}$ and
$3 \mathrm{~d}$. The first effect may be related to the release of induced cold-work defects or dislocations, which facilitate the austenite $\rightarrow$ martensite transformation, with a corresponding increase in $\mathrm{Ms}^{18,23}$. The second one is related to an increase in the amount of martensite which is transformed to austenite ${ }^{24}$. This effect can be clearly appreciated from Figure 5, where electrical resistivity of each phase (austenite and martensite) is plotted as a function of the HT temperature. Here, the values for the sample without HT $(\rho=1440 \mathrm{nW} \cdot \mathrm{m})$ correspond, as expected, to the highest value. The asreceived sample is shown as a reference. Solid and empty symbols correspond to the austenite and martensite phases, respectively.

From Figure 5, it seems clear that:

1. A strong decrease in resistivity (from 1440 to 1123 $\mathrm{nW} \cdot \mathrm{m})$ results after heat treatment at the lowest temperature of $330^{\circ} \mathrm{C}(\mathrm{HT} 1)$, whereas transformation is insignificant as illustrated by the very small change in resistivity between martensite and austenite. This seems to indicate that HT1 allows a very important release of cold work, although this stress release is not enough to promote the formation of a sufficiently large fraction of grains and therefore the martensitic transformation is only initiated at this juncture;

2. For the $\mathrm{HT} 2$ at $390^{\circ} \mathrm{C}$ again a significant decrease in resistivity to $\sim 880 \mathrm{n} \Omega \cdot \mathrm{m}$ is observed. However, in this case not only the release of cold work is taking place, but also the recovering of grains starts and the martensitic transformation, as confirmed by TEM and DSC;

3. When HT temperature increases, a small decrease in resistivity to $\sim 870$ or $\sim 800 \mathrm{nW} \bullet \mathrm{m}$ is observed (for the
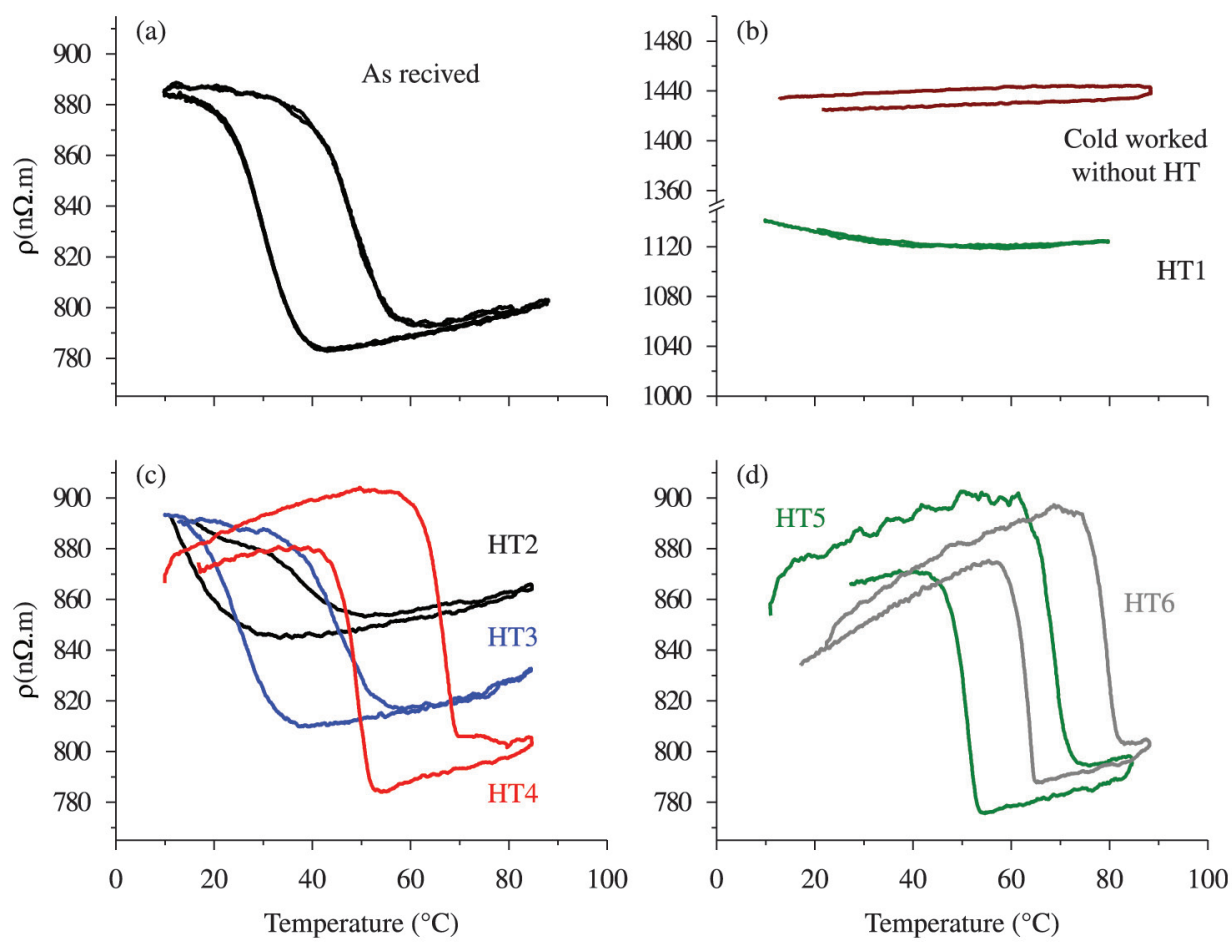

Figure 4. Electrical resistivity vs. Temperature for austenite and martensite phases. 
martensite phase or the phase austenite, respectively). Here, the release of cold work is still present, as confirmed by the microhardness results, but the recovery of grains and the amount of martensitic transformation becomes significant.

These results with those observed by TEM and microhardness, seem to indicate that for HT1, HT2, and HT3 the release of cold work plays an important roll in the

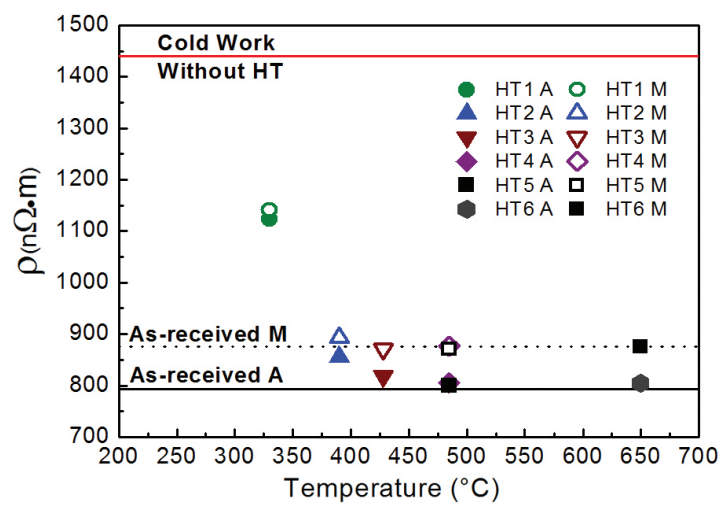

Figure 5. Electrical resistivity vs. HT temperature for austenite and martensite phases.

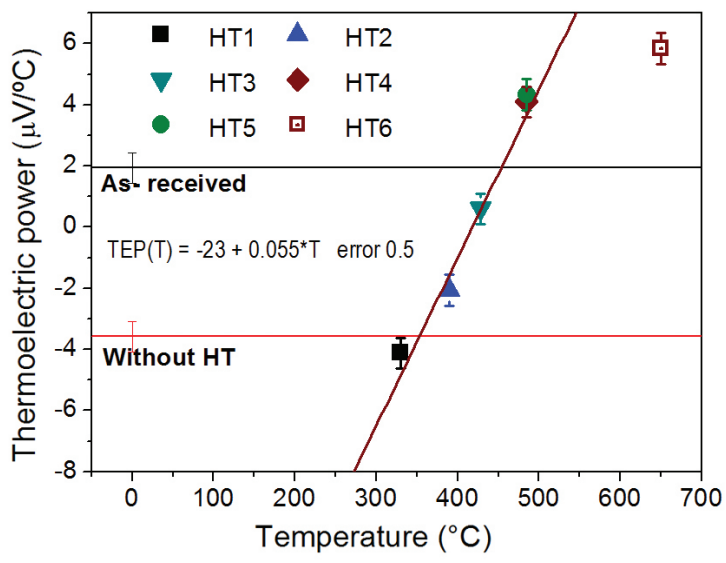

Figure 6. TEP vs. temperature of heat treatment.

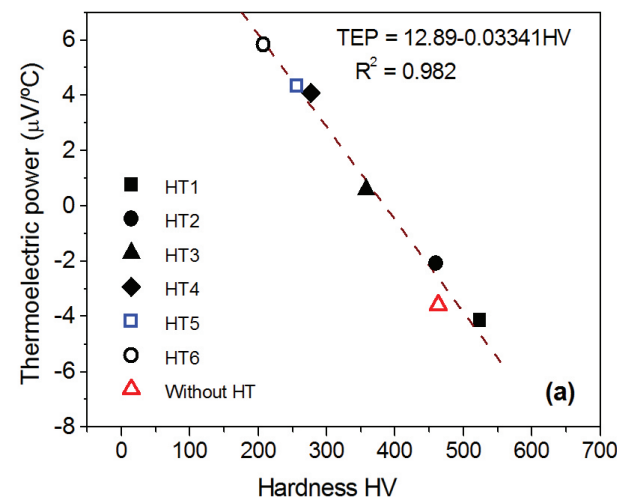

kinetics of recovery of the crystalline state. From 485 to $650^{\circ} \mathrm{C}$ (HT4-HT6), grain growth becomes more important, and resistivity attains a minimum constant value, i.e. there is not a significant change in the resistivity between those temperatures (see Figure 5).

\subsection{Thermoelectric power}

Thermoelectric Power (TEP) of the alloy has also been studied for each HT shown in Figure 6. Although values of TEP are relative to the nature of the couple of metals and they are affected by the composition, temperature and microstructure, the results are in the range of those reported in the literature ${ }^{16,25}$. The values for the as-received and without heat treatment samples are shown as reference. In general, the formation of an important density of dislocations with cold work causes a decrease in TEP, as it has been reported before ${ }^{16-18}$. On other hand, heat treatments promote an increase in TEP values for two reasons: the diminution of dislocations and the increase in grain size. In addition, it is worth noting that in Figure 6 the lowest value in TEP corresponds to the sample after HT1. This is a similar behavior but inverse to the one observed from microhardness measurements where, contrary to what was expected, the highest value corresponds to the sample after HT1 and not to the sample without heat treatment.

These results may be a consequence of the particular microstructures developed after heat treatments at low temperatures (i.e., HT1 and probably HT2), where a combination of a highly anisotropic amorphous phase produced by cold work, together with incipient nanograin formation, could lead to anomalous behavior in microhardness and TEP measurements. Moreover, TEP technique has been shown to be very sensitive to anisotropy induced by wire drawing of Ti-Ni-Cu or by an applied stress during stress assisted two-way memory effect ${ }^{16,18,25}$. This suggests that the anisotropy induced by cold work and then, modified by HT1, should be the cause of this phenomenon in the microhardness and TEP behaviors.

Then, TEP and microhardness seem to be affected in the same way by the same variables. Thus, in order to look for evidence of such influence we have plotted thermoelectric power vs. microhardness as shown in

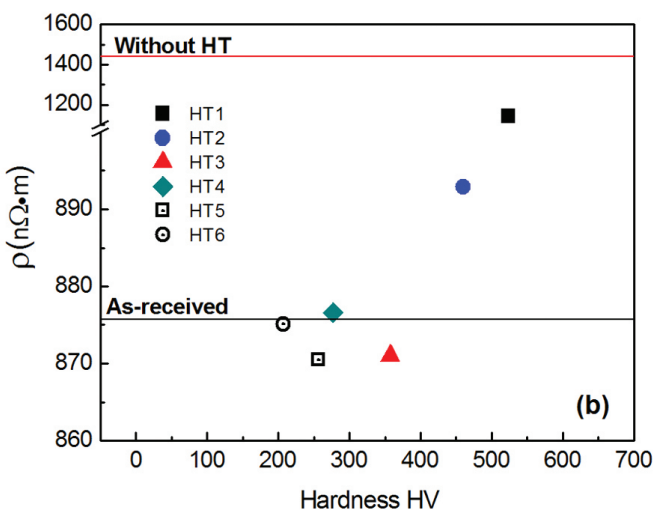

Figure 7. (a-b) TEP and $\rho$ vs. microhardness respectively for each HT. 
Figure 7a. Interestingly, a clear linear correlation was found, given by TEP $=-0.0334 \cdot \mathrm{HV}+12.89$, with a linear correlation coefficient of -0.0334 , while for $\rho$ Vs. microhardness (Figure 7b), no linear correlation is obtained. This correlation between TEP and microhardness is important because by knowing the TEP of an alloy, its mechanical response and microstructure can be predicted. This may not be possible with electrical resistivity analysis.

\section{Conclusions}

After the cold work, a complete amorphous microstucture is observed in the Ti-45.0Ni-5.0Cu (\% at.) alloy. As the alloy is heat treated at low temperature $\left(330^{\circ} \mathrm{C}\right)$, a release of the induced cold work is observed mainly due to the release of internal stress, although the incipient formation of nanograins is also important. This particular mixture of microstructures, where a high anisotropy should be present, might be responsible for the observed unusual behavior in microhardness and TEP measurements after low temperature heat treatments. Moreover, from the results of electrical resistivity and TEM, it can be confirmed that, the martensitic transformation takes place in microstructures with grains smaller than $30 \mathrm{~nm}$. For heat treatments at intermediate temperatures $\left(428^{\circ} \mathrm{C}\right.$, for example), the release of stress and the formation and the growth of nanograins both play important roles. Above $428^{\circ} \mathrm{C}$, the growth of nanograins seems to be more important than other changes as suggested by the electrical resistivity results and microstructure analysis.

\section{References}

1. Otsuka K and Ren X. Physical metallurgy of Ti-Ni-based shape memory alloys. Progress in Materials Science. 2005; 50(5):511678. http://dx.doi.org/10.1016/j.pmatsci.2004.10.001

2. Bertacchini OW, Lagoudas DC and Patoor E. Thermomechanical transformation fatigue of TiNiCu SMA actuators under a corrosive environment. Part I: experimental results. International Journal of Fatigue. 2009; 31(10):1571-1578. http://dx.doi.org/10.1016/j.ijfatigue.2009.04.012

3. Nam TH, Yu CA, Lee YJ and Liu YN. Fabrication of Ti-Ni alloys for proportional control. International Journal of Applied Electromagnetics and Mechanics. 2006; 23(1-2):9-15.

4. Gonzalez CH, Oliveira CAN, Pina EAC, Urtiga Filho SL, Araújo Filho OO and Araújo CJ. Heat treatments and thermomechanical cycling influences on the R-phase in Ti-Ni shape memory alloys. Materials Research. 2010; 13(3):325331. http://dx.doi.org/10.1590/S1516-14392010000300008

5. Craciunescu $\mathrm{C}$ and Hamdy AS. The effect of copper alloying element on the corrosion characteristics of Ti-Ni and ternary $\mathrm{Ni}-\mathrm{Ti}-\mathrm{Cu}$ meltspun shape memory alloy ribbons in $0.9 \% \mathrm{NaCl}$ solution. International Journal of Electrochemical Science. 2013; 8(8):10320-10334.

6. Zhang HJ and Qiu CJ. A TiNiCu thin film micropump made by magnetron co-sputtered method. Materials Transactions. 2006; 47(3):532-535. http://dx.doi.org/10.2320/matertrans.47.532

7. López-Cuéllar E, Guénin G and Morin M. Behaviour of strain-resistivity coupled measurements of $\mathrm{Ti}-\mathrm{Ni}-\mathrm{Cu}$ wires during thermal cycling under constant stress. Materials Science
With the DSC technique was not possible to detect the martensitic transformation of nanograins after HT1, but electrical resistivity was able to detect it, which indicates a greater sensitivity of this technique. Results of TEP seems to indicate that the TEP of the Ti-Ni-Cu is affected by the dislocations induced during cold working, the orientation of variants from cold working and the change of grain boundary defects caused by the thermomechanical process. A linear correlation between TEP and microhardness has been found (with a correlation coefficient of -0.0334), showing predictable relationship related to microstructural changes by heat treatment. Then, the TEP technique can be used to predict the mechanical response and the microstructure of the alloy after this amorphization-recrystallization. Finally, it is concluded that a stable or metastable microstructure (degree of amorphization, nanograin size, dislocations density, etc.) is obtained for each heat treatment temperature, since the evolution in microhardness, DSC, resistivity and TEP for a sample heat treated at the same temperature $\left(485^{\circ} \mathrm{C}\right)$ for different times ( 1 and 2 hours) shows only small differences in the corresponding values, i.e. they do not depend on time.

\section{Acknowledgments}

We would like to mention those who provided help in this work, the MATEIS -INSA de Lyon, SWISSMETAL company for the provided alloy and Paul Riley. This work was also supported by the project 107462 and 82515 from CONACYT.

and Engineering: A. 2004; 378(1-2):115-118. http://dx.doi. org/10.1016/j.msea.2003.10.333

8. Araújo CJ and Lima IST. Electrical activation under constant load of Ti-Ni and $\mathrm{Cu}-\mathrm{Zn}-\mathrm{Al}$ SMA wire actuators. In: Proceedings of 18th International Congress of Mechanical Engineering; 2005; Ouro Preto, Brasil. Rio de Janeiro: ABCM; 2006. p. 409-416. ABCM Symposium Series in Mechatronics 2.

9. Likhachev VA, Pomytkin SP and Shimanskii SR. Effect of thermomechanical treatment on the sequence of phase transformations in TiNi base alloys. Metal Science and Heat Treatment. 1989; 31(8):571-577 http://dx.doi.org/10.1007/ BF00802680

10. Khelfaoui F and Guénin G. Influence of the recovery and recrystallization processes on the martensitic transformation of cold worked equiatomic Ti-Ni alloy. Materials Science and Engineering: A. 2003; 355(1-2):292-298. http://dx.doi. org/10.1016/S0921-5093(03)00068-6

11. Sadiq H, Wong MB, Al-Mahaidi R and Zhao XL. The effects of heat treatment on the recovery stresses of shape memory alloys. Smart Materials and Structures. 2010; 19(3):1-7. http:// dx.doi.org/10.1088/0964-1726/19/3/035021

12. Jiang S, Zhang Y and ZHAO Y. Dynamic recovery and dynamic recrystallization of NiTi shape memory alloy under hot compression deformation. Transactions of Nonferrous Metals Society of China. 2013; 23(1):140-147. http://dx.doi. org/10.1016/S1003-6326(13)62440-1

13. Kazemi-Choobi K, Khalil-Allafi J and Abbasi-Chianeh $\mathrm{V}$. Investigation of the recovery and recrystallization 
processes of Ni50.9Ti49.1 shape memory wires using in situ electrical resistance measurement. Materials Science and Engineering: A. 2012; 551:122-127. http://dx.doi. org/10.1016/j.msea.2012.04.106

14. Koike J, Parkin DM and Nastasi M. Crystal-to-amorphous transformation of NiTi induced by cold rolling. Journal of Materials Research. 1990; 5(7):1414-1418. http://dx.doi. org/10.1557/JMR.1990.1414

15. Khelfaoui F, Thollet G and Guenin G. Microstructural evolution kinetics after plastic deformation of equiatomic Ti-Ni alloy during isothermal annealings. Materials Science and Engineering: A. 2002; 338(1-2):305-312. http://dx.doi. org/10.1016/S0921-5093(02)00085-0

16. López Cuéllar E, Guenin G and Morin M. Study of the stressassisted two-way memory effect of a $\mathrm{Ti}-\mathrm{Ni}-\mathrm{Cu}$ alloy using resistivity and thermoelectric power techniques. Materials Science and Engineering: A. 2003; 358(1-2):350-355. http:// dx.doi.org/10.1016/S0921-5093(03)00328-9

17. Perez M, Massardier V and Kleber X. Thermoelectric power applied to metallurgy: principle and recent applications. International Journal of Materials Research. 2009; 100(10):1461-1465. http://dx.doi.org/10.3139/146.110198

18. Lopez-Cuéllar E. Fatigue par cyclage thermique sous contrainte de fils à mémoire de forme Ti-Ni-Cu après différents traitements thermomécaniques. [Thèse]. Villeurbanne: Institut National des Sciences Appliquées de Lyon ; 2002. p. 5967.

19. Olbricht J, Yawny A, Condó AM, Lovey FC and Eggeler G. The influence of temperature on the evolution of functional properties during pseudoelastic cycling of ultra fine grained NiTi. Materials Science and Engineering: A. 2008; 481482:142-145. http://dx.doi.org/10.1016/j.msea.2007.01.182

20. Lara-Rodriguez GA, Gonzalez G, Flores-Zúñiga H and CortésPérez J. The effect of rapid solidification and grain size on the transformation temperatures of $\mathrm{Cu}-\mathrm{Al}-\mathrm{Be}$ melt spun alloys. Materials Characterization. 2006; 57(3):154-159. http:// dx.doi.org/10.1016/j.matchar.2005.12.017

21. Wood JV and Shingu PH. The effect of processing conditions and subsequent heat treatment on the transformation behavior of some rapidly solidified copper-base shape memory alloys. Metallurgical Transactions A. 1984; 15(3):471-480. http:// dx.doi.org/10.1007/BF02644970

22. Jicmon $G$, Coşmeleață $G$ and Batalu D. Investigation of some electrical properties of niti wires presenting the shape memory effect. UPB Scientific Bulletin, Series B. 2009; 71(4):131-138.

23. Khelfaoui $F$ and Guénin G. Annealing of cold-worked equiatomic Ti-Ni alloy followed by DSC and TEP methods. Journal de Physique IV. 2001; 11:81-86. http://dx.doi. org/10.1051/jp4:2001814

24. Peultier B, Ben Zine T and Patoor E. Macroscopic constitutive law for SMA: application to structure analysis by FEM. Materials Science and Engineering A. 2006; 438:454-458. http://dx.doi.org/10.1016/j.msea.2006.01.104

25. Lopez Cuéllar E, Guénin G. and Morin M. Study of reorientation of martensite variants under stress in Ti-Ni-Cu by resistivity and by thermoelectric power techniques. Journal de Physique IV. 2001; 11(Pr8):89-94. 